\title{
Experimental investigation of the dynamic load sharing of planetary gearboxes
}

\author{
J. Götz ${ }^{1}(\mathbb{D}) \cdot$ F. Siglmüller ${ }^{1}$ M. Fürst' ${ }^{1}$ M. Otto ${ }^{1}$ K. Stahl' \\ Received: 23 March 2021 / Accepted: 17 June 2021 / Published online: 8 July 2021 \\ (c) The Author(s) 2021
}

\begin{abstract}
Due to their compactness and power density, planetary gearboxes are used for a wide range of high-performance applications in the automotive, aviation and marine sector. Aerospace applications in particular benefit from a full use of the load capacity potential to meet the requirements for lightweight construction and efficiency. Against this background, the load sharing between the individual planetary gears plays a decisive role. A uniform load sharing enables the design of the single tooth meshes without load increases and oversizing. However, due to manufacturing and assembly deviations, a perfect load sharing is technically not feasible. These load increases are taken into account in the standard calculation of the load capacity of planetary gearboxes by the mesh load factor $\mathrm{K} \gamma$. The load sharing in planetary gearboxes is influenced by a number of factors, such as the rigidity of shafts, housing and bearings, the number of planets, the quality of the gear wheels and the operating conditions. Detailed simulations or extensive experimental measurements are required to determine the exact load sharing. For new designs of planetary gearboxes, there are only simplified assumptions available, based on the number of planets and a rough estimation of the operating range. Especially additional dynamic forces, due to operation in high-speed ranges or near resonance frequencies, can lead to a considerable change of the dynamic load sharing compared to the static load sharing and cause an uncertainty in the design. Thus, in this paper the dynamic load sharing behaviour is investigated from 0 to $6800 \mathrm{rpm}$ sun speed for different loads. Based on the experimental data recommendations for the design of planetary gearboxes under consideration of the operating conditions are derived.
\end{abstract}

Availability of data and material Not applicable

Code availability Not applicable

J. Götz

goetz@fzg.mw.tum.de
1 Gear Research Centre (FZG) Technical University of Munich, Garching, Germany 


\section{Experimentelle Untersuchung der dynamischen Lastaufteilung in Planetengetrieben}

\section{Zusammenfassung}

Aufgrund ihrer Kompaktheit und Leistungsdichte werden Planetengetriebe für eine Vielzahl von Hochleistungsanwendungen im Automobil-, Luftfahrt- und Marinebereich eingesetzt. Insbesondere Anwendungen in der Luft- und Raumfahrt profitieren von einer vollen Ausnutzung des Tragfähigkeitspotenzials, um die Anforderungen an Leichtbau und Effizienz zu erfüllen. Vor diesem Hintergrund spielt die Lastaufteilung auf die einzelnen Planetenräder eine entscheidende Rolle. Eine gleichmäßige Lastaufteilung ermöglicht die Auslegung der einzelnen Zahneingriffe ohne Lastüberhöhung und Überdimensionierung. Aufgrund von Fertigungs- und Montageabweichungen ist eine ideal gleichmäßige Lastaufteilung jedoch technisch nicht realisierbar. Lasterhöhungen infolge von ungleicher Lastaufteilung werden bei der Standardberechnung der Tragfähigkeit von Planetengetrieben durch den Lastaufteilungsfaktor $\mathrm{K} \gamma$ berücksichtigt. Die Lastaufteilung in Planetengetrieben wird durch eine Reihe von Faktoren beeinflusst, wie z. B. die Steifigkeit von Wellen, Gehäuse und Lager, die Anzahl der Planeten, die Qualität der Zahnräder und die Betriebsbedingungen. Um die genaue Lastaufteilung zu ermitteln, sind detaillierte Simulationen oder umfangreiche experimentelle Messungen erforderlich. Für Neukonstruktionen von Planetengetrieben liegen nur vereinfachte Annahmen vor, die auf der Anzahl der Planeten und einer groben Abschätzung des Betriebsbereichs beruhen. Insbesondere zusätzliche dynamische Kräfte, bedingt durch den Betrieb im Hochdrehzahlbereich oder in der Nähe von Resonanzfrequenzen, können zu einer erheblichen Änderung der dynamischen Lastaufteilung gegenüber der statischen Lastaufteilung führen und eine Unsicherheit bei der Auslegung verursachen. Daher wird in dieser Arbeit das dynamische Lastaufteilungsverhalten von 0 bis $6800 \mathrm{U} / \mathrm{min}$ Sonnendrehzahl für verschiedene Lasten untersucht. Basierend auf den experimentellen Daten werden Empfehlungen für die Auslegung von Planetengetrieben unter Berücksichtigung der Betriebsbedingungen abgeleitet.

\section{Introduction}

The planetary load sharing behaviour can be described by the mesh load factor $K_{\gamma}$ according to ISO 6336-1 [15] and is calculated based on the individual normal tooth forces of each mesh. Besides gear errors (quality) and assembly deviations, the load sharing is also influenced by the stiffness or rigidity of shafts, housing and bearings, the number of planets and the operating conditions [23]. Different standards and classifications such as AGMA 6123-C16 [1], BS EN 61400-4 [3], DNVGL-CG-0036 [7] and the "Guideline for the Certification of Wind Turbines" [8] give a rough estimation of $K_{\gamma}$ for different applications, but merely based on the number of planets. Only in AGMA 6123-B06 [1] a distinction into four basic grades of requirements regarding the operational speed range is provided.

Against this background, numerous theoretical and experimental investigations of the planetary load sharing behaviour and its influencing parameters were carried out. 2D or 3D lumped-parameter models with different degrees of freedom form the more simplified simulation models [4, $9,14,17,20,24]$, whereas more complex hybrid models combine analytical approaches for describing the tooth contact and finite element calculations for the overall deformations of the gearbox components [16, 19, 22]. Kahraman [17] investigates the influence of assembly deviations and manufacturing errors on the dynamic load sharing behaviour of a planetary spur gearbox with four planets to establish basic design guidelines. Using a floating sun gear significantly improves the dynamic load share. Manufactur- ing errors, such as run-out errors, or assembly variations, such as tangential planet position errors, affect the load sharing substantially. Those results correspond well with the work of Ren et al. [24] (herringbone planetary gear set), Iglesias et al. [14] (spur planetary gear set) as well as Leque and Kahraman [20] (helical planetary gear set). Besides gear errors and assembly variations, the number of planets and the load have an essential influence [20, 22, 25]. While higher loads improve the load share between the different planet gears due to higher elastic deformations, a higher number of planets results in a higher sensitivity regarding errors. Through more complex models with full finite element calculations, Kahraman and Vijayakar [19] (spur planetary gear set), James and Harris [16] and Ligata et al. [22] (both helical planetary gear sets) analysed the influence of the stiffness and deformation of the central members of a planetary gearbox and attest an improved load share by stiffness reduction. Hidaka, Terauchi et al. perform several experimental studies on a spur gear planetary gear set to characterize the static and dynamic load sharing behaviour. The results are presented in a series of reports [11-13] and coincide with Cunliffe [4] and Hayashi [10]. At high rotational speeds and for low loads the load sharing behaviour is influenced significantly by the dynamic system behaviour of the planetary gear system, whereas the dynamic load share for low speeds with sufficient distance to resonance areas corresponds well with the static one. Further experiments are conducted by Ligata et al. [21, 22] and Boguski et al. [2] to analyse in detail the influence of manufacturing errors and ring gear stiffness on the quasi- 


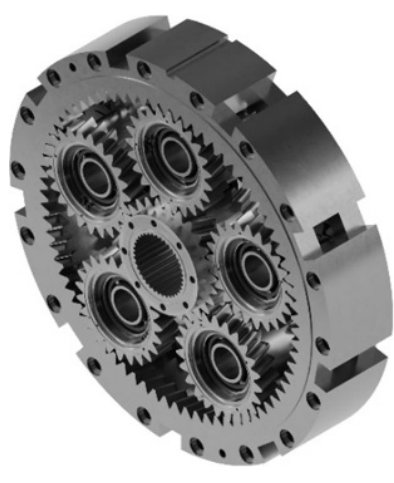

Fig. 1 5-planet double- helical planetary gear set

static load sharing of different planetary gear set configurations. The experimental data is often used to validate simulation models. The results show good compliance and confirm the calculated results $[16,18,25]$. In the previous works, the load sharing behaviour of spur and helical planetary gears is extensively studied, but double-helical gears are rarely addressed [24]. Due to the combination of low mesh excitation with avoiding axial forces, double-helical planetary gear sets are used in modern high-performance and high-speed applications and form essential drive trains. In this study, the load sharing behaviour of such a double-helical planetary gear set is experimentally investigated under static and dynamic operation conditions to evaluate the influence of speeds under consideration of the vibration characteristics of the system.

\section{Test specimen}

This study uses a five-planet double-helical planetary gear set, which is shown in Fig. 1. Table 1 lists the basic design parameters of the test gears. The sun and planets are manufactured as double-helical gears, while the ring gear consists of two internal helical gears with opposite helical angles.

The stagger angle $\gamma_{s}$, which defines the relative angular position of the two gear halves with respect to each other, is set to zero. The sun gear is the input and the carrier the output shaft, as the ring gear is fixed to the housing. Sun and planet gears are case hardened, while the ring gear is nitrated. After the heat treatment, all gears are ground and super-finished to achieve very precise flank geometries with a high surface quality. One of the five planet gears shows slightly poorer gear qualities compared to the other ones (see Table 1: max. values for planet 2, min. values for other planets) but is still within the desired tolerances. Standard flank modifications (tip relieves and crowning) are used to ensure a uniform contact pressure distribution in all gear meshes. The planet gears are equally spaced and mounted with two cylindrical roller element bearings on the planet pins. To avoid undesired influences due to mass unbalances the parts with high rotational speeds (e.g. sun shaft and sun gear wheel) are balanced according to DIN ISO 21940-11 [5] to grade 2 and the assembled carrier to grade 6.3. For the experiments in this study, no additional planet position errors or gear errors are applied. The planet pin hole errors in the carrier resulting from the manufacturing process are determined by a 3D measurement. The maximum pin hole position error in tangential direction is $64.6 \mu \mathrm{m}$ and in radial direction $31.5 \mu \mathrm{m}$. Compared to the maximum amount of tip relief at the planet gear with $26 \mu \mathrm{m}$, this position error is not completely negligible.

\section{Test rig and test matrix}

The planetary test gearbox was designed to fit into the backto-back planetary gearbox test rig at the Gear Research Cen-
Table 1 Gear data of the test gear set

\begin{tabular}{|c|c|c|c|c|c|}
\hline & & & Sun & Planet & Ring \\
\hline No. of teeth & $\bar{z}$ & - & 26 & 23 & 74 \\
\hline Pressure angle & $\alpha_{n}$ & $\circ$ & 27 & & \\
\hline Module & $m_{n}$ & $\mathrm{Mm}$ & 3.91 & & \\
\hline Helix angle & $\beta$ & $\circ$ & 15 & & \\
\hline \multirow{2}{*}{$\begin{array}{l}\text { Active face width } \\
\text { (each half) }\end{array}$} & \multirow[t]{2}{*}{$b$} & \multirow[t]{2}{*}{$\mathrm{Mm}$} & 21 & & - \\
\hline & & & - & & 19 \\
\hline $\begin{array}{l}\text { Transv. contact ratio } \\
\text { (Standard design) }\end{array}$ & $\varepsilon_{\alpha}$ & - & Approx & 1.5 & \\
\hline $\begin{array}{l}\text { Overlap ratio } \\
\text { (one helix bank) }\end{array}$ & $\varepsilon_{\beta}$ & - & Approx & 0.5 & \\
\hline Centre distance & $a$ & $\mathrm{Mm}$ & 99.156 & & \\
\hline No. of planets & $N$ & - & 5 & & \\
\hline Quality of total profil deviation (min/max) [6] & $F_{\alpha}$ & - & $2 / 4$ & $2 / 6$ & $1 / 3$ \\
\hline Quality of total helix deviation (min/max) [6] & $F_{\beta}$ & - & $4 / 6$ & $2 / 6$ & $8 / 8$ \\
\hline Quality of total index devation (min/max) [6] & $F_{P}$ & - & $4 / 4$ & $1 / 4$ & $4 / 6$ \\
\hline
\end{tabular}




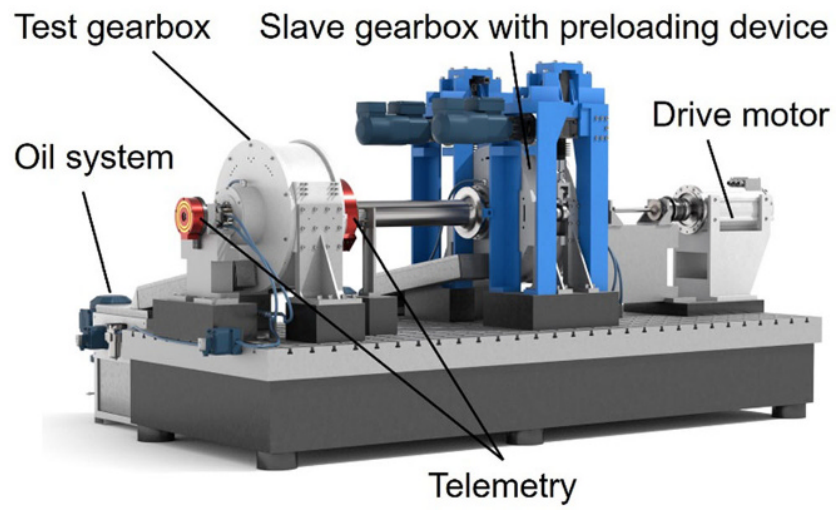

Fig. 2 Back-to-back planetary gearbox test rig

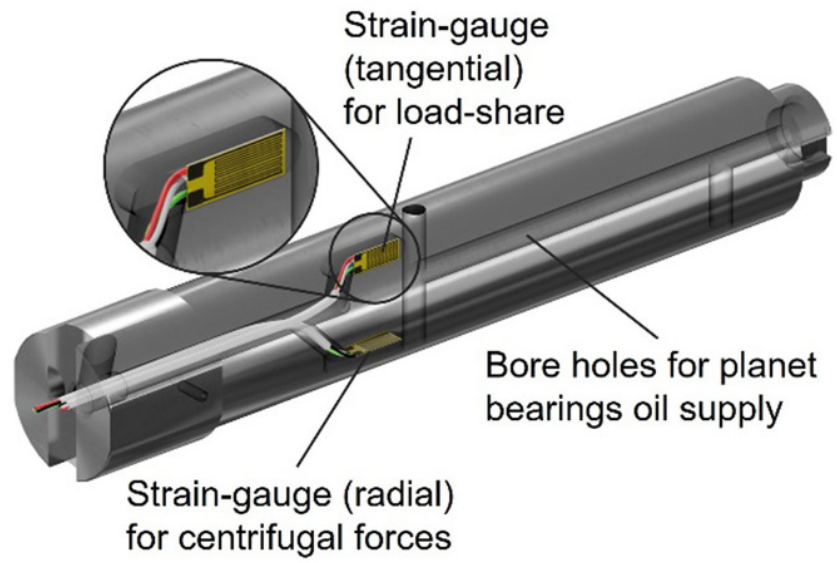

Fig. 3 Exemplary planet pin with 2 strain gauges for measuring tangential and radial strains due to mesh forces and CF loads

tre (FZG) of the Technical University of Munich. The test rig is shown in Fig. 2 and a detailed description of the principle function and measurement devices can be found in [26]. Two identical gearboxes are mounted in the test gearbox and slave gearbox housing, respectively. Both gearboxes are connected by the carrier and sun shaft. The ring gear of the test gearbox is fixed to the housing, while the ring gear of the slave gearbox can be twisted automatically by jackscrew hoist gears to preload the planetary gearboxes. A maximum torque of $15000 \mathrm{Nm}$ at the carrier shaft can be applied. The electrical drive motor is attached with couplings to the sun shaft and provides a maximum rotational speed of $8000 \mathrm{rpm}$. The planetary gearbox in the test housing is equipped with most of the sensors, thus is the main subject of this study.

The static load share tests are performed with a constant single input (sun) speed of $150 \mathrm{rpm}$ at eight discrete carrier shaft torque levels between 1500 and $15000 \mathrm{Nm}$. The dynamic load share tests are performed during speed rampups from 0 to $6800 \mathrm{rpm}$ sun speed at all eight torque levels to obtain load share data over the complete operational range.

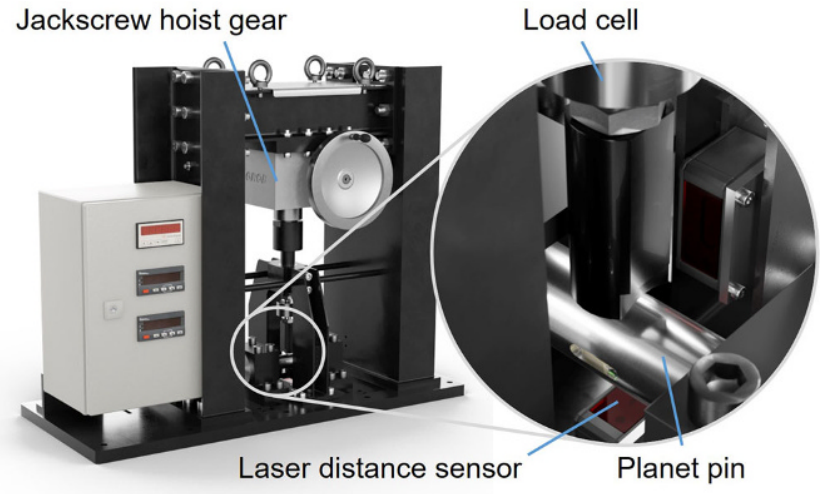

Fig. 4 Overview of planet pin calibration device

\section{Instrumentation, data collection and sensor calibration}

The planet load sharing behaviour is obtained by continously monitoring the tangential bending strains at each planet pin. These bending strains are caused by the combined tangential mesh forces of each planet gear with the sun and ring gear respectively. For this purpose one strain gauge (HBM type 1-LY41-6/1000) with $1000 \Omega$ resistance is mounted in the middle of each planet pin at the location of maximum bending due to the mesh forces, which are transmitted by two cylindrical roller element bearings to each planet pin. One planet pin is equipped with an additional strain gauge, that measures the strain in radial direction as a result of the centrifugal forces at higher rotational speeds. For the measurement positions a groove is machined into the outer surface of the planet pin to provide sufficient room and protect the strain gauge from the inner races of the cylindrical roller element bearings during assembly. The depth of the groove is limited to the absolutely necessary minimum to ensure sufficient distance to the neutral axis for the bending strain measurement. An exemplary planet pin with two strain gauges for measuring the tangetial and radial strains is shown in Fig. 3.

Since the ring gear is fixed to the housing, the planet carrier acts as the output shaft and rotates. For measuring the strains an inductive telemetry is used. The sensor cables are led through several bores to the rotor of the telemetry on the carrier shaft. There, each strain gauge is interconnected to a Wheatstone quarter bridge and the bridge voltage is digitized and contactlessly transmitted to the stationary data acquisition system. All measurement data is collected and stored by an NI PXIe- 8880 system (mounted in a NI PXIe1085 chassis). Additionally, angular positions of sun and carrier shaft are measured by an optical absolute angular position sensor system, consisting of a RESOLUT readhead and a RESA ring, manufactured by Renishaw. During each test run the strain data is recorded with a sample rate 


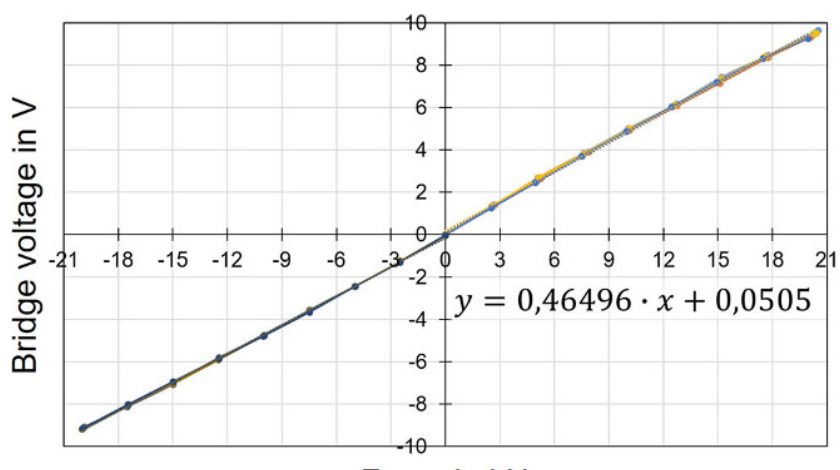

Force in $\mathrm{kN}$

Fig. 5 Exemplary result of a planet pin calibration. Applied force range from -20 to $20 \mathrm{kN}$ and averaging of five consecutive test procedures

of $30 \mathrm{kHz}$. Due to the manual application process of the strain gauges and the differences between the sensors of one charge, all strain gauges have to be calibrated to be able to measure even small differences in the load sharing. For this purpose a planet pin calibration device is designed, which is illustrated in Fig. 4.

The planet pin is mounted exactly in the same way as in the planet carrier and is then manually loaded with a jackscrew hoist gear up to $20 \mathrm{kN}$. The strain is measured with the same inductive telemetry which is also used during the tests to avoid errors due to differences in the amplifiers and data acquisition system. The loading and unloading process is performed several consecutive times and the data is used to generate a linear regression line for the correlation of force and strain. An additional laser distance sensor is used to check the reliability of the loading and unloading process by measureing the deflection. Fig. 5 shows an exemplary result of a planet pin strain gauge calibration.

Before a test run starts, the test rig is heated up to $40^{\circ} \mathrm{C}$. Tooth mass temperatures of sun and ring gear as well as the oil inlet temperatures are monitored to ensure all components have the same temperature. This procedure is important because all strain gauges at the pins are not compensated against temperature-induced elongation in the quarter bride circuit. After heating up, the strain data is recorded under no-load condition to obtain a zero-torque offset point for all strain gauges. This is essential, because even under no-load, the planet pins are bent due to small assembly deviations of the carrier. After that, the torque level is applied to the back-to-back test rig configuration and the drive motor accelerates the rig according to the speed requirement with a speed rate of $30 \mathrm{rpm} / \mathrm{s}$. The stationary speed is generally kept for $90 \mathrm{~s}$, whereas the maximum speed during a speed ramp-up is just kept for $5 \mathrm{~s}$. During all test runs the two separate oil systems, respectively for test and slave

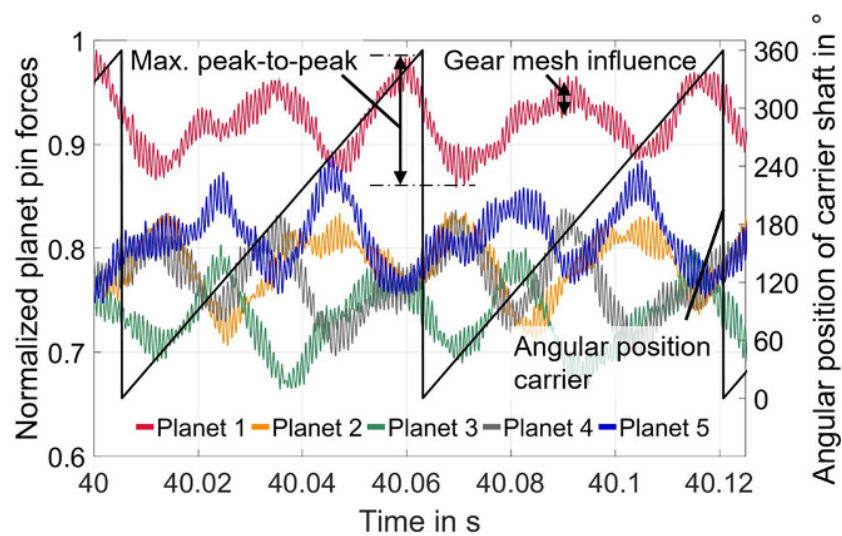

Fig. 6 Exemplary segment of load sharing test at 4000 rpm sun speed and $10000 \mathrm{Nm}$ carrier torque (partial load). Planet pin forces normalized to maximum overall planet pin force

gearbox, controlled the oil inlet temperature to $40^{\circ} \mathrm{C}$ with an accuracy of $\pm 2{ }^{\circ} \mathrm{C}$.

\section{Data evaluation and computation of load sharing}

The recorded strain data of all five sensors is used to calculate the load share of the double-helical planetary test gearbox. In a first step the raw data is filtered to exclude data transmission errors of the telemetry. The zero-torque offset value, derived from the tests under no-load condition, is used to correct the time data of each sensor channel and eliminate the influence of the assembly process of the carrier. Subsequently the results of the planet pin calibration are applied to calculate the planet pin tangential forces $F_{P, n}(t)$ based on the measured tangential strain $\varepsilon_{P, n}(t)$ for each planet $n$ according to Eq. 1, where $m$ denotes the gradient of the linear regression.

$F_{P, n}(t)=m \cdot \varepsilon_{P, n}(t)$

The forces $F_{P, n}(t)$ are summed up to find the total pin force such that the percentage represented by a gauge of this total force value represents the load carried by that planet $n$. Mathematically, the mesh load factor $K_{\gamma, n}(t)$ of the $n$-th planet is defined as

$K_{\gamma, n}(t)=\frac{F_{P, n}(t)}{\sum_{i=1}^{N} F_{P, i}(t)}$

The average value of $K_{\gamma, n}(t)$ over the test time of $90 \mathrm{~s}$ is chosen to represent the mean portion of load carried by planet $n$. Fig. 6 displays a 0.125 s segment of a load share test at $4000 \mathrm{rpm}$ input speed and $10000 \mathrm{Nm}$ load. It includes the planet pin calibration based forces for all five planets 


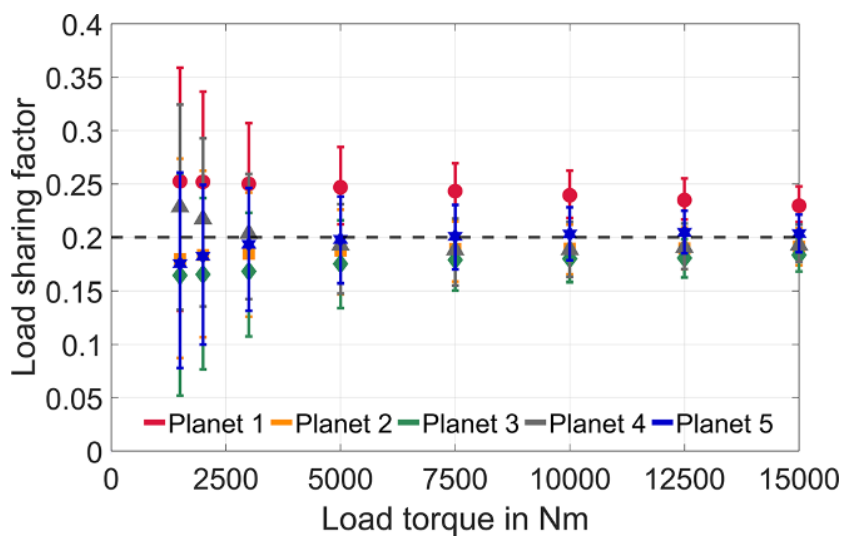

Fig. 7 Static load share at $150 \mathrm{rpm}$ input speed. Average value (dots), maximum peak-to-peak load share value (error bar)

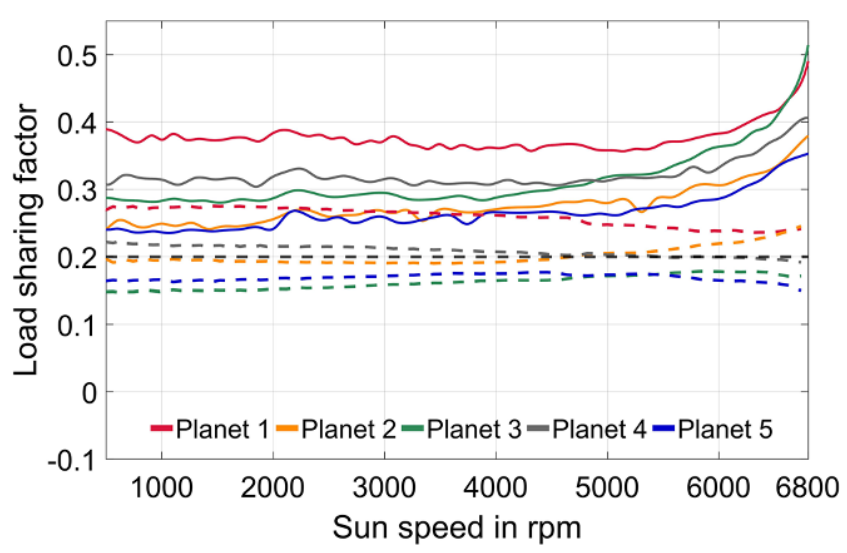

Fig. 8 Dynamic load share during speed ramp-up from 500 to $6800 \mathrm{rpm}$ at $1500 \mathrm{Nm}$ load torque. Average value (dotted line), envelope of maximum peak-to-peak value (solid line)

(normalized to the overall maximum planet pin force) as well as the carrier angular position. Due to the high sampling rate of $30 \mathrm{kHz}$ the impact of the gear mesh is also clearly visible. The planet pin forces fluctuate about $1.5 \mathrm{kN}$ during a carrier rotation as a resulting combination of manufacturing deviations, the gear mesh and system dynamics. This peak-to-peak band (see Fig. 6) is used to define the range of load share variation and characterize the influence of the dynamic system behaviour of the gear set.

\section{Results}

In the first step, the quasi-static load share at $150 \mathrm{rpm}$ input speed and a variation of torque from 1500 to $15000 \mathrm{Nm}$ is evaluated as a reference for the tests under higher rotational speeds. Fig. 7 shows the load share according to Eq. 2 for all five planets. The errorbar denotes the maximum peakto-peak value during the test run.

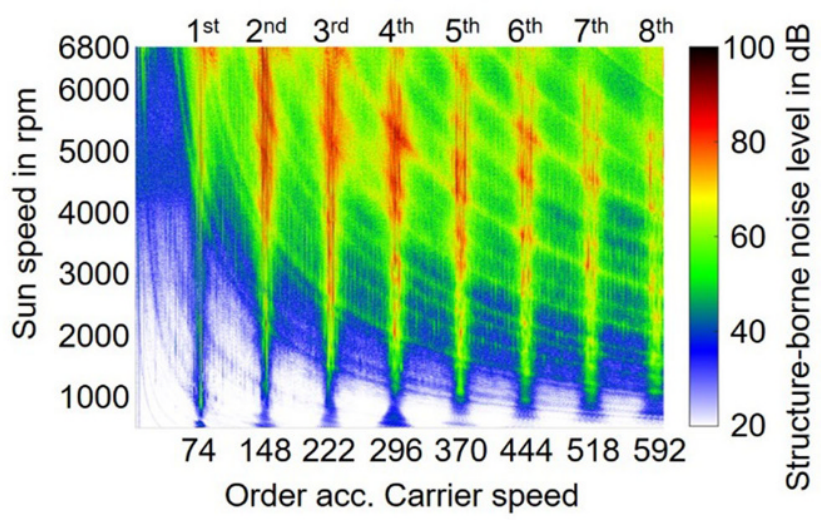

Fig. 9 Order-diagram of radial structure-borne noise at the ring gear during seep ramp-up to $6800 \mathrm{rpm}$ and $1500 \mathrm{Nm}$ load torque

The static load share behaviour is well comparable to earlier experimental and simulative results of spur or helical planetary gearboxes $[2,21]$. Under low load, the individual gear meshes are slightly loaded and the deflections of gearbox components are minor. Thus manufacturing and assembly deviations dominate the load sharing behaviour, resulting in higher average load sharing factors (dots in Fig. 7) as well as maximum peak-to-peak value (error bar in Fig. 7). With increasing load, the elastic deflections grow and balance the manufacturing deviations and errors, hence yielding to smaller load sharing factors and reduced peakto-peak values. Planet 1 carries the highest load over the complete torque range. The maximum of $25.2 \%$ is reached at $1500 \mathrm{Nm}$ and drops to $23.0 \%$ at $15000 \mathrm{Nm}$. The difference between the load share values of all five planets at quasi-static conditions and full load are quite small, since the gear quality (see Table 1) as well as the manufacturing erros of the carrier are small. A remaining slightly unequal load sharing under maximum load is plausible, since planet carrier, ring gear, and housing of the test rig are very stiff. Results for the dynamic load share behaviour is displayed in Fig. 8 for a speed ramp-up to $6800 \mathrm{rpm}$ input speed and $1500 \mathrm{Nm}$ load. The load share factors are calculated for each time point respectivley. For better visibility only the average value (dotted line) and the envelope of maximum values of peak-to-peak load share factors (solid line) are shown for each planet, since the envelope is arragned symmetrically around the mean average value. Up to an input speed of around $5000 \mathrm{rpm}$, the average as well as the the envelope values indicate no significant changes in the load sharing.

For higher speeds from 6000 to $6800 \mathrm{rpm}$, the maximum and minimum peak-to-peak values start to grow exponentially, and the gradient of the average values also indicates an increase. Considering the order-diagram of an acceleration sensor measuring the structure-borne noise at the fixed ring gear in radial direction (see Fig. 9, measurement details 


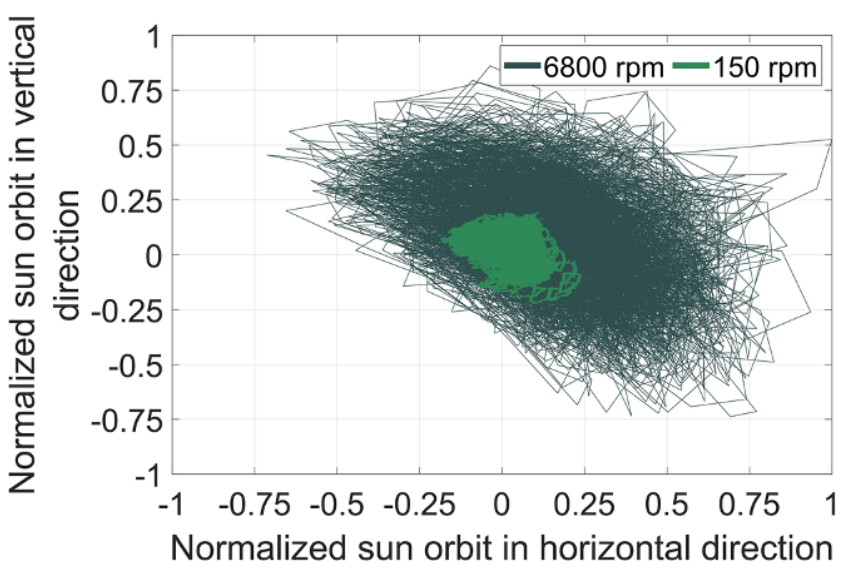

Fig. 10 Sun orbit measurement at $1500 \mathrm{Nm}$ load torque, normalized to the maximum measured orbit value. Quasi-static conditions (150 rpm input speed) and dynamic conditions (6800 rpm input speed)

described in [26]), an increase of the structure-borne noise level of the 1st, 2nd, 3rd and 4th mesh order is recognizable in the same speed range (6000 to $6800 \mathrm{rpm})$. Furthermore, hyperbolas, representing eigenfrequencies, are indicating possible resonance areas slightly above $6800 \mathrm{rpm}$ for the 1 st and 3 rd mesh order with increased vibration amplitudes in the gear mesh. Another indicator for increased excitation in planetary gearboxes is the ovalization of the sun orbit. Fig. 10 illustrates the the sun orbit of the test gearbox for five carrier rotations at $150 \mathrm{rpm}$ and $6800 \mathrm{rpm}$ respectively (measurement method described in [26]). The measured values are normalized to the maximum sun orbit value. At high rotational speeds the amplitudes of the orbit are significantly increased (cantilevered bearing support), leading to higher reaction forces in the gear mesh and thus, increased amplitudes of the dynamic load share factor. Similar to the static load sharing behaviour, the dynamic load sharing improves significantly with higher loads. Fig. 11 displays the dynamic load share factor during a speed rampup from 500 to $6800 \mathrm{rpm}$ at full load $(15000 \mathrm{Nm})$. The average load share factors as well as the maximum peak-to-peak envelope is minimized and can be assumed to be constant over the complete speedrange, even in the critical speed range of 6000 to $6800 \mathrm{rpm}$.

\section{Conclusion}

In this study the dynamic load sharing behavior of a five planet double-helical planetary gear set was investigated experimentally on a back-to-back test rig. A high-frequency strain measurement at the planet pins was used to calculate the load share factors based on the bending strains. Comparing the load share under high rotational speeds with quasistatic conditions, the following conclusions and design recommendations can be drawn:

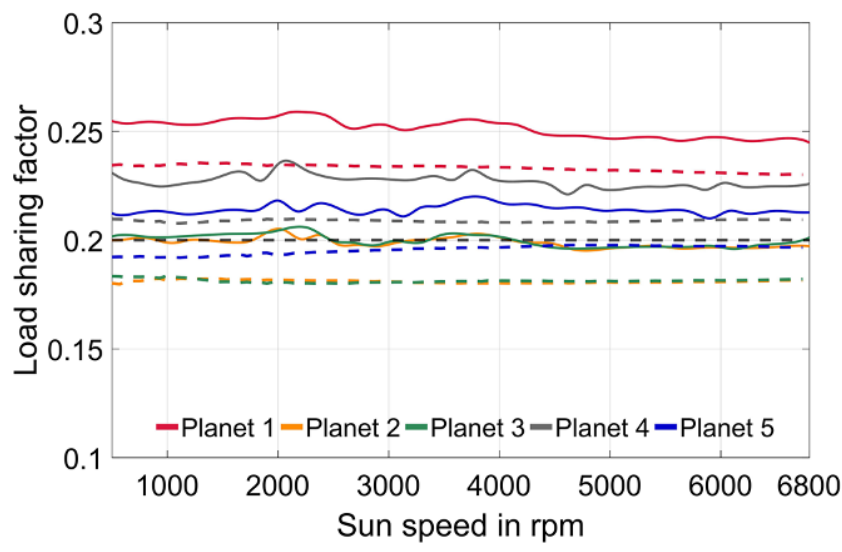

Fig. 11 Dynamic load share during speed ramp-up from 500 to $6800 \mathrm{rpm}$ at $15000 \mathrm{Nm}$ load torque (full load). Average value (dotted line), envelope of maximum peak-to-peak value (solid line)

- The load share factors determined under quasi-static condition are applicable for a wide operational range of speed and torque. Dynamic effects on the load sharing behaviour have to be considered only at very high speeds (also depending on the ressonance area of the gear meshes).

- Although high-precision gears and components are used in this study, the results show relative large differences in load sharing under low load when comparing the individual planets. Thus, including the tolerance chain into the design process is recommended.

- At high speeds and low loads, the load sharing behaviour is significantly influenced by the vibration behavior of the drive train. Resonance areas can lead to increased load share values and amplitudes. The operational range of the planetary gearbox should be checked for such ressonance areas (tooth numbers and masses) to avoid them during continous operation.

- Not only the gear mesh affects the load share under high rotational speeds, but also the movement of the sun. This coincides with previous experiments in the literature [12]. A tradeoff between the adjustability of the sun to improve the load sharing for lower speeds and a reasonable bearing arrangement for high speeds is necessary.

Since these experiments are based on high precision gears and gearbox components, further investigations have to consider typical manufacturing and assembly errors, such as planet position errors or excentricities.

Funding The test rig was funded by the Federal Ministry of Economic Affairs and Energy (BMWi) as per resolution of the German Federal Parliament under grant number 20T1504 (ASIMOV).

Author Contribution Not applicable 
Funding Open Access funding enabled and organized by Projekt DEAL.

Conflict of interest J. Götz, F. Siglmüller, M. Fürst, M. Otto and $\mathrm{K}$. Stahl declare that they have no competing interests.

Open Access This article is licensed under a Creative Commons Attribution 4.0 International License, which permits use, sharing, adaptation, distribution and reproduction in any medium or format, as long as you give appropriate credit to the original author(s) and the source, provide a link to the Creative Commons licence, and indicate if changes were made. The images or other third party material in this article are included in the article's Creative Commons licence, unless indicated otherwise in a credit line to the material. If material is not included in the article's Creative Commons licence and your intended use is not permitted by statutory regulation or exceeds the permitted use, you will need to obtain permission directly from the copyright holder. To view a copy of this licence, visit http://creativecommons.org/licenses/by/4. $0 /$.

\section{References}

1. AGMA 6123-C16: Design Manual for Enclosed Epicyclic Gear Drives, American Gear Manufacturers Association, Alexandria, 2016

2. Boguski B, Kahraman A, Nishino T (2012) A new method to measure planet load sharing and sun gear radial orbit of planetary gear sets. J Mech Des 134(7):1151

3. BS EN 61400-4: Wind turbines-Part 4: Design requirements for wind turbine gearboxes, British Standard Institution, 2013

4. Cunliffe F, Smith JD, Welbourn DB (1974) Dynamic tooth loads in epicyclic gears. J Eng Ind 96(2):578-584

5. DIN ISO 21940-11: Mechanische Schwingungen - Auswuchten von Rotoren Teil 11: Verfahren und Toleranzen für Rotoren mit starrem Verhalten, Deutsches Institut für Normung e. V., Berlin, 2017

6. DIN ISO 1328-1: Zylinderräder - ISO Toleranzsystem - Teil 1: Definitionen und zulässige Werte für Abweichungen an Zahnflanken, Deutsches Institut für Normung e. V., Berlin, 2018

7. DNVGL-CG-0036: Calculation of gear rating for marine transmissions, DNV GL, 2015

8. Rules and Guidelines Industrial Services IV-Part 1: Guideline for Certification of Windturbines, Germanischer Lloyd, Hamburg, 2010

9. Gu X, Velex P (2012) A dynamic model to study the influence of planet position errors in planetary gears. J Sound Vib 331(20):4554-4574

10. Hayashi T, Li XY, Hayashi I, Endo K, Watanabe W (1986) Measurement and some discussions on dynamic load sharing in planetary gears. Bull JSME 29(253):2290-2297
11. Hidaka T, Terauchi Y (1976) Dynamic behavior of planetary gear: 1st report load distribution in planetary gear. Bull JSME 19(132):690-698

12. Hidaka T, Terauchi Y, Ishioka K (1976) Dynamic behavior of planetary gear: 2nd report, displacement of sun gear and ring gear. Bull JSME 19(138): 1563-1570

13. Hidaka T, Terauchi Y, Ishioka K (1979) Dynamic behavior of planetary gear: 4th report, influence of the transmitted tooth load on the dynamic increment load. Bull JSME 22(168):877-884

14. Iglesias M, Fernandez Del Rincon A, de-Juan A, Garcia P, DiezIbarbia A, Viadero F (2017) Planetary transmission load sharing: manufacturing errors and system configuration study. Mech Mach Theory 111:21-38

15. ISO 6336-1: Calculation of load capacity of spur and helical gears-Part 1: Basic principles, introduction and general influence factors, International Organization for Standardization, Genf, 2019

16. James B, Harris O (2002) Predicting unequal planetary load sharing due to manufacturing errors and system deflections, with validation against test data. In: SAE 2002 World Congress \& Exhibition

17. Kahraman A (1994) Load sharing characteristics of planetary transmissions. Mech Mach Theory 29(8):1151-1165

18. Kahraman A (1999) Static load sharing characteristics of transmission planetary gear sets: model and experiment. Int Congr Expo. https://doi.org/10.4271/1999-01-1050

19. Kahraman A, Vijayakar S (2001) Effect of internal gear flexibility on the quasi-static behavior of a planetary gear set. J Mech Des 123(3):408-415

20. Leque N, Kahraman A (2017) A three-dimensional load sharing model of planetary gear sets having manufacturing errors. J Mech Des 139(3):33302

21. Ligata H, Kahraman A, Singh A (2008) An experimental study of the influence of manufacturing errors on the planetary gear stresses and planet load sharing. J Mech Des 130(4):690

22. Ligata H, Kahraman A, Singh A (2009) Influence of gear rim deflections on planetary gear set behavior. In: ASME 2009 International Design Engineering Technical Conferences and Computers and Information in Engineering Conference, San Diego, California, USA, pp 95-103

23. Neubauer B (2016) Lastverteilung und Anregungsverhalten in Planetengetriebesystemen. Dissertation, Technische Universität, München

24. Ren F, Qin D, Lim TC, Lyu S (2014) Study on dynamic characteristics and load sharing of a herringbone planetary gear with manufacturing errors. Int J Precis Eng Manuf 15(9):1925-1934

25. Singh A, Kahraman A, Ligata H (2008) Internal gear strains and load sharing in planetary transmissions: model and experiments. J Mech Des 130(7):85

26. Weinberger U, Siglmüller F, Götz J, Otto M, Stahl K (2019) Scaling of planetary gear stages according to gear excitation similarity. Proc Inst Mech Eng Part C J Mech Eng Sci 233(21-22):7246-7256 